\title{
Egg laying and incubation rhythm of the Chinese Grouse (Tetrastes sewerzowi) at Lianhuashan, Gansu, China
}

\author{
Mei Shi ${ }^{1,2}$, Yun Fang ${ }^{1}$, Jin-ming Zhao ${ }^{3}$, Siegfried Klaus ${ }^{4}$, Yingxin Jiang ${ }^{1}$, Jon E. Swenson ${ }^{5}$ and Yue-Hua Sun ${ }^{1 *}$ (1)
}

\begin{abstract}
Background: Incubating birds must balance the conflict between thermal needs of the developing embryos and their self-maintenance needs for energy. The Chinese Grouse (Tetrastes sewerzowi) lives in high mountain conifer forests and faces energy stress, cold environment, and predation pressure. Females might adjust incubation rhythm to adapt to these constraints.
\end{abstract}

Methods: Two methods were used to investigate egg laying and incubation pattern of the Chinese Grouse; 25 nests were monitored by data loggers and 12 nests by infrared video cameras.

Results: Female Chinese Grouses usually laid an egg every 2 days. The incubation period was 28-31 days. Overall incubation constancy for Chinese Grouse was 93\%. The females took 5.0 recesses per day and 34\% of all 1696 recesses were taken in the crepuscular period. The average recess duration was $20.3 \mathrm{~min}$. Females took more and shorter recesses in the latter part of incubation. The females who allocated more time to foraging had a higher reproductive success.

Conclusions: Probably due to its high egg/body mass ratio, the Chinese Grouse has a long laying interval of $49 \mathrm{~h}$. We suggest that, due to energy stress, females have relatively more recesses and they increase the number of recesses as incubation progresses. To compensate for the embryos' thermal needs, they extend the incubation period and shorten the recess duration in this cold environment.

Keywords: Body mass, Chinese Grouse, Environment temperature, Incubation pattern, Nest attentiveness

\section{Background}

In precocial birds, especially in those where only one sex incubates, egg laying and incubation are important stages of reproductive investment, and may represent critical energy bottlenecks, especially in harsh environments (Wiebe and Martin 1995, 1997, 2000). Incubating individuals must balance the conflict between thermal needs of the developing embryos and their self-maintenance needs by leaving the nest to forage (Wiebe and Martin 2000; Conway and Martin 2000a; Coates and Delehanty 2008). Also, incubating birds have to adjust their

\footnotetext{
*Correspondence: sunyh@ioz.ac.cn

${ }^{1}$ Key Laboratory of Animal Ecology and Conservation Biology, Institute

of Zoology, Chinese Academy of Sciences, Beijing 100101, China

Full list of author information is available at the end of the article
}

incubation rhythms based on physical conditions and environmental factors.

In smaller species, environmental factors have a greater effect on incubation rhythm and smaller birds are thought to have a greater need for food during incubation (Afton 1980). Large-bodied birds have greater energy reserves and can spend more time on the nest, but in periods of stress, small-bodied birds might not have enough nutrient reserves to complete incubation (Gloutney and Clark 1991) and need more time off nests for foraging (Manlove and Hepp 2000; Camfield et al. 2010). Also, birds living in areas with low temperatures have a higher daily energy expenditure, but foraging away from the nest is almost twice as costly as incubating a four-egg clutch (Piersma et al. 2003). Because low ambient temperatures allow eggs to cool quickly, birds 
might be required to show higher nest attentiveness in cold climates (Chalfoun and Martin 2007). Martin (2002) has shown that colder ambient temperatures can result in higher attentiveness, such as Anna's (Calype anna) and Black-chinned Hummingbirds (Archilochus alexandri) nesting in California, which took longer nest attentiveness than Purple-crowned Fairy (Heliothryx barroti) in the warm lowland tropics of Panama (Vleck 1981).

The Chinese Grouse (Tetrastes sewerzowi) is an endemic bird distributed in Gansu, Qinghai, Sichuan, Yunnan, and Tibet in western China (Sun 2000), along the high mountain conifer forests at altitudes between 2700 and $4200 \mathrm{~m}$ on the eastern edge of the Tibetan Plateau. These birds typically experience a decrease in mass during reproduction, which is usually considered to be an indication of reproductive stress (Cucco and Malacarne 1997). The Chinese Grouse is the smallest grouse in the sub-family of Tetraonidae (Sun et al. 2005). On the other hand, nutritious foods are limited in spring, as willows (Salix spp.) are the main food resources for the birds (Zhao et al. 2017), so nutrient constraint possibly exists during the egg-formation and incubation periods (Wang et al. 2010). During the pre-incubation period, the proportion of time allocated for vigilance by male and time for foraging by female Chinese Grouse is the highest recorded among monogamous grouse species (Lou et al. 2017). This probably benefited the female by reducing the danger of predation, increasing her probability of survival, and allowing more time for her to forage for more nutritious food, such as herb leaves and insects, to increase her energy reserves (Lou et al. 2017). Good body condition at the beginning of the breeding season has been associated with large egg volumes and early laying and body mass is positively related to food abundance during the incubation of Wilson's Storm Petrels (Oceanites oceanicus) (Quillfeldt et al. 2006).

How does the Chinese Grouse deal with the cold weather, high altitude, short breeding time, and nutrient stress during the egg-laying and incubation period? In this study, we explored the egg-laying and incubation rhythms of Chinese Grouse and analyzed the strategies Chinese Grouse uses to deal with these disadvantages. We predicted that more feeding during incubation is important for Chinese Grouse reproductive success.

\section{Methods}

\section{Study area}

We conducted the study during 1999-2016 at the Lianhuashan Nature Reserve $\left(34^{\circ} 45^{\prime}-35^{\circ} 06 \mathrm{~N}\right.$, $\left.103^{\circ} 27^{\prime}-103^{\circ} 51^{\prime} \mathrm{E}\right)$ in southern Gansu Province, central China. Our research station was at the altitude of $2850 \mathrm{~m}$, surrounded by forest dominated by fir (Abies fargesii), spruce (Picea asperata), birch (Betula utilis), and many species of willow. The average annual temperature in the reserve is $5.1-6.0{ }^{\circ} \mathrm{C}$, with recorded extremes of $34.0{ }^{\circ} \mathrm{C}$ and $-27.1^{\circ} \mathrm{C}$ at an altitude of $2100 \mathrm{~m}$. For more information, see Sun et al. (2003).

\section{Field methods}

The nests of Chinese Grouse are located at the bases of fir, spruce, birch and willow trees. Nesting materials are mainly mosses, leaves and dry twigs. Nests were found by locating radio-tracked females, searching paired males' territories or from reports by local people, who received a reward (Sun et al. 2003; Zhao et al. 2018).

We equipped 25 nests with data loggers (Germin Data Loggers LTD, UK, Tiny Talk II) to record the egg temperatures when the females were on and off their nests, when the temperatures were higher and lower, respectively. In 1999, we equipped 4 nests with thermo-sensors fixed at the bottom of the nests, with a cable (length $<3 \mathrm{~m})$ connected to the data loggers. The temperature data recorded in this way were generally lower than the temperature of the egg. However, changes in data logger temperatures should be proportional to those of the eggs, so we could record the nest attendance of the females. In 2000 and 2001, we placed artificial eggs in the center of 16 nests for monitoring both nest attendance and egg temperature. The artificial eggs were from abandoned clutches, and filled with paraffin wax, and thermo-sensors were buried in it (Persson and Göransson 1999). This arrangement did not seem to affect the behaviour of the females, as no females abandoned their nests after we placed the dummy eggs in their nests. We put the thermo-sensors or dummy eggs into the nests as soon as we located them. If the clutch was unfinished, we could record the egg laying intervals. The data loggers were kept dry and covered in plastic boxes. The data loggers were programmed to record temperatures every $6.0 \mathrm{~min}$. In 2010, we monitored 5 nests. The other operations were the same as in 2000, except that the data loggers were programmed to record temperatures every minute. We revisited the nests every 7 days to download the data and restart the loading, mostly without disturbing the hens from the nests. If we disturbed the hens while downloading the data, we excluded the results from that day from the analyses.

The timing and duration of recesses were interpreted from changes in egg $(n=21)$ or nest $(n=4)$ temperatures associated with the departure and return of the females, as shown on the strip charts. Short temperature drops (lasting only one measurement, $6 \mathrm{~min}$ ) were likely a result of females repositioning themselves on the nest and moving the eggs; they were not considered to be recesses. Four irregular records from three nests were recorded (two at day time from one nest: 186, $1068 \mathrm{~min}$; 
two at night from two nests: 186, $205 \mathrm{~min}$ ). All three nests hatched successfully. These were most likely associated with predation attempts and all data from these days were excluded from analyses. We defined the overall incubation constancy as the percentage of the time the females spent on the nests during the entire incubation period. Partial incubation was a less regular form of incubation that can occur from the beginning of egg laying to shortly after clutch completion (Wang and Beissinger 2011). Nests were regarded as successful when at least one egg was hatched. We determined nest age by considering that eggs were laid every other day with a mean incubation period of 28 days for successful nests (Sun et al. 2003). For the unsuccessful nests that had been found during incubation, we speculated nest age as Zhao et al. (2019).

In both 2000 and 2001, one data logger was used to record the forest temperature in our study area during the laying and incubating period. All monitored nests were located throughout the study area, so we selected a nest randomly to record the environment temperature. To avoid disturbing the incubating female, thermo-sensors and data logger were hung on a tree $1.5 \mathrm{~m}$ high from the ground and $50 \mathrm{~m}$ away from the Chinese Grouse nest. Nest site temperatures might differ from our data logger records. However, as the Chinese Grouse made open nests without much concealment, we assumed that there was not a big difference.

During 2013 to 2016, we monitored 12 nests with infrared video cameras (The Ltl Acorn Ltl-6210 M). With its highly sensitive passive Infra-Red sensor, the camera detects the sudden change of ambient temperature caused by moving animals in a region of interest, triggering the camera to take pictures/videos. Thus when a female moved, we obtained videos. By this means, we knew the exact time that a female left and arrived at a nest. We mounted cameras on trunks about $0.5 \mathrm{~m}$ away from the nests. The video lasted $10 \mathrm{~s}$ for every triggering and 3 pictures for confirmation. We recorded date, time, and frame number on video images electronically.

\section{Data analysis}

Data from nests monitored less than 7 days were not included in calculating the recess rates and incubation constancy. We excluded video footages that were interrupted by camera malfunction, loss of power, or disturbance from changing batteries, memory cards, and long-time recess because of predation. Nineteen samples using the data logger and nine from the video camera were included in our analyses. All recesses occurred from 05:30 to 20:30. Nest constancy was calculated in days, and the average was taken.
We conducted a mixed effects linear model, the daily number of recesses as the dependent variable and year, method, nest age, recess duration as fixed factors, with individual as a random factor. And we used a mixed effects linear model to test how the fixed factors year, method, nest age, hour and number of recesses affected recess duration, with individual as a random factor. There was a correlation between year and method. To exclude the effect of method on year, we separated all data to three groups: datalog6, datalog1 and camera, then reanalyzed. To examine how incubating females adjusted recess timing, we grouped all individuals into these groups: reproduction successful and failed, tracked and untracked. We used $t$ tests to test the difference in incubation patterns between groups. The data were analyzed using the program $\mathrm{R}$. All values were expressed as mean \pm SD.

\section{Results}

We monitored the egg laying of 8 females. Females laid eggs at midday, between 10:59 and 15:45 (time arriving at nest, $n=16$ ), except for one female that arrived at the nest at 07:27 and spent $6 \mathrm{~h}$ there when laying its sixth egg. The laying time of all six of one female's eggs occurred within two and half hours (12:32-15:11). Females usually laid one egg every 2 days, except for one instance of 3 days. The laying intervals of five females were $49.0 \pm 1.3 \mathrm{~h}(n=18)$. Females spent variable amounts of time on the nests when laying eggs. Less time was spent when laying the first four eggs $(71.3 \pm 19.8 \mathrm{~min}, n=9)$ than for laying the fifth and sixth eggs $(162.8 \pm 89.0 \mathrm{~min}$, $n=8)$. Full incubation started in the early morning $(6: 30-$ $8: 30, n=8)$. Two females started right after laying the sixth egg, five on the next day, and one on the third day.

We included 28 nests of data in our analyses of nest attendance of Chinese Grouse, for a total of 201 days during 1999 to 2001, 62 days in 2010, and 108 days during 2013 to 2016 (Table 1). Based on the 14 females for which we had documented when they started incubating and hatching of the eggs, the incubation period of Chinese Grouse was around 29.8 (28-31) days.

The overall incubation constancy was $92.8 \pm 2.0 \%$ $(n=376$ days). The females took $5.0 \pm 1.0 \quad(n=376)$ recesses per day with the average recess length of $20.3 \pm 7.7$ min $(n=1696)$. Three methods (data $\log -6 \mathrm{~min}$, data log-1 min and camera) affected neither number of recesses nor recess duration. Recess number and recess duration had a significantly negative relationship $(\mathrm{df}=367.018, t=-6.016, p<0.001$, Fig. 1b). Time of day significantly affected recess duration $(\mathrm{df}=1658.666$, $t=9.948, p<0.001$, Fig. 1a). Recess number increased significantly $(\mathrm{df}=370.879, t=3.397, p<0.001$, Fig. $1 \mathrm{c})$, but recess duration decreased $(\mathrm{df}=1391.690, t=-1.781$, 
Table 1 The number of daily recesses and nest constancy of Chinese Grouse females during the incubation period at Lianhuashan Nature Reserve, Gansu, China

\begin{tabular}{|c|c|c|c|c|c|c|}
\hline $\begin{array}{l}\text { Year-female } \\
\text { number }\end{array}$ & Nest age & Number of daily recesses ${ }^{a}$ & Recess duration $(\mathrm{min})^{\mathbf{b}}$ & Nest constancy (\%) ${ }^{c}$ & Hatched/Failed & $\begin{array}{l}\text { Radio- } \\
\text { tracked }\end{array}$ \\
\hline 99-01 & $2-26$ & $5.36 \pm 1.16(23)$ & $28.93 \pm 7.59(129)$ & $89.16 \pm 1.96$ & $\mathrm{H}$ & Y \\
\hline $99-02$ & $5-16$ & $4.83 \pm 0.79(12)$ & $22.84 \pm 5.49(57)$ & $92.31 \pm 1.17$ & $\mathrm{~F}$ & Y \\
\hline $99-03$ & $18-24$ & $5.57 \pm 0.82(7)$ & $22.76 \pm 10.23(39)$ & $91.19 \pm 1.62$ & $\mathrm{H}$ & Y \\
\hline 00-01 & $22-30$ & $3.56 \pm 0.53(9)$ & $21.48 \pm 7.06(31)$ & $94.72 \pm 1.18$ & $\mathrm{H}$ & N \\
\hline 00-02 & $6-29$ & $5.25 \pm 0.61(24)$ & $18.87 \pm 6.66(126)$ & $93.12 \pm 1.16$ & $\mathrm{H}$ & Y \\
\hline 00-03 & $7-25$ & $4.84 \pm 0.96(19)$ & $20.66 \pm 6.67(92)$ & $93.05 \pm 1.22$ & $\mathrm{~F}$ & $\mathrm{~N}$ \\
\hline 00-04 & $5-28$ & $4.67 \pm 0.87(24)$ & $23.52 \pm 7.93(113)$ & $92.40 \pm 1.29$ & $\mathrm{H}$ & Y \\
\hline 00-05 & $8-21$ & $4.69 \pm 0.63(13)$ & $22.78 \pm 7.42(64)$ & $92.66 \pm 1.07$ & $\mathrm{H}$ & Y \\
\hline 00-06 & $13-25$ & $6.15 \pm 0.81(13)$ & $21.19 \pm 6.31(78)$ & $91.30 \pm 1.69$ & $\mathrm{~F}$ & Y \\
\hline 00-07 & $12-19$ & $4.50 \pm 0.53(8)$ & $18.83 \pm 4.34(36)$ & $94.11 \pm 0.75$ & $\mathrm{~F}$ & $\mathrm{~N}$ \\
\hline 01-01 & 8-18 & $4.36 \pm 0.67(11)$ & $19.38 \pm 6.69(48)$ & $94.13 \pm 1.09$ & $\mathrm{~F}$ & Y \\
\hline 01-02 & $15-29$ & $6.07 \pm 0.70(15)$ & $15.9 \pm 5.06(92)$ & $93.39 \pm 1.08$ & $\mathrm{H}$ & Y \\
\hline 01-03 & $10-26$ & $5.19 \pm 0.75(16)$ & $16.36 \pm 6.48(84)$ & $94.11 \pm 1.20$ & $\mathrm{~F}$ & $\mathrm{~N}$ \\
\hline 01-04 & $13-20$ & $4.29 \pm 0.49(7)$ & $22.32 \pm 5.06(25)$ & $93.54 \pm 0.57$ & $\mathrm{~F}$ & Y \\
\hline 10-01 & $1-13$ & $4.54 \pm 0.66(13)$ & $21.97 \pm 5.48(59)$ & $93.08 \pm 1.26$ & $F$ & $\mathrm{~N}$ \\
\hline 10-02 & $2-23$ & $4.64 \pm 0.58(22)$ & $14.38 \pm 4.09(101)$ & $95.42 \pm 0.73$ & F & Y \\
\hline 10-03 & $13-20$ & $4.75 \pm 0.71(8)$ & $23.56 \pm 8.94(36)$ & $92.27 \pm 1.60$ & $\mathrm{~F}$ & Y \\
\hline 10-04 & $19-27$ & $4.89 \pm 0.78(9)$ & $22.37 \pm 7.4(43)$ & $92.42 \pm 0.91$ & $\mathrm{H}$ & Y \\
\hline 10-05 & $17-26$ & $5.30 \pm 0.82(10)$ & $20.55 \pm 5.71(52)$ & $92.58 \pm 1.17$ & $\mathrm{H}$ & $\mathrm{N}$ \\
\hline 13-01 & $2-16$ & $4.41 \pm 0.79(15)$ & $21.09 \pm 7.38(52)$ & $93.29 \pm 1.91$ & $\mathrm{H}$ & Y \\
\hline $13-02$ & $7-18$ & $4.45 \pm 0.52(11)$ & $23.6 \pm 9.36(10)$ & $93.08 \pm 2.65$ & $\mathrm{~F}$ & Y \\
\hline 13-03 & $15-24$ & $5.18 \pm 0.60(11)$ & $19.86 \pm 8.8(43)$ & $93.02 \pm 1.68$ & $\mathrm{H}$ & $\mathrm{N}$ \\
\hline 14-01 & $10-20$ & $4.15 \pm 0.69(11)$ & $18.28 \pm 5.78(39)$ & $94.56 \pm 1.48$ & $\mathrm{H}$ & Y \\
\hline $14-02$ & $3-12$ & $5.90 \pm 0.88(10)$ & $18.71 \pm 9.61(45)$ & $92.32 \pm 1.76$ & $\mathrm{H}$ & Y \\
\hline $15-01$ & $2-8$ & $4.29 \pm 0.49(7)$ & $17.64 \pm 4.93(28)$ & $94.85 \pm 0.86$ & $\mathrm{H}$ & Y \\
\hline $16-01$ & $19-25$ & $6.00 \pm 0.76(7)$ & $18.21 \pm 7.56(29)$ & $92.96 \pm 1.29$ & $\mathrm{H}$ & Y \\
\hline $16-02$ & $2-25$ & $6.13 \pm 0.85(24)$ & $16.24 \pm 7.51(109)$ & $93.53 \pm 1.81$ & $\mathrm{H}$ & N \\
\hline $16-03$ & $14-25$ & $4.33 \pm 0.49(12)$ & $16.28 \pm 4.22(36)$ & $95.21 \pm 0.71$ & $\mathrm{H}$ & Y \\
\hline
\end{tabular}

a Mean $\pm \mathrm{SD}(n), n$ was days excluding those disturbed by research action and irregular recesses

${ }^{\mathrm{b}}$ Mean $\pm \mathrm{SD}(n), n$ was recesses excluding those missing record of female going out or coming back

c Mean \pm SD, $n$ (constancy) $=n$ (number of daily recesses), nest constancy $=(1440 \mathrm{~min}-t$ (female staying out of nest) $/ 1440 \mathrm{~min}) \times 100 \%$

$p=0.075$, Fig. 1d) as nest age progressed. Recess duration was also affected by year (data logger- $6 \mathrm{~min}, t=-3.820$, $p<0.001$; camera, $t=-3.426, p<0.001)$. Of the 1696 recesses, $34.4 \%$ were taken in the crepuscular periods (before 6:30 and after 18:30, Fig. 2). In all 376 monitored days, we recorded $262(69.7 \%)$ dawn recesses and 321 (85.4\%) dusk recesses (Fig. 2). Dawn recess duration was shortest $(17.9 \pm 6.4 \mathrm{~min}, n=261)$ and dusk recess duration was longest ( $25.3 \pm 8.3 \mathrm{~min}, n=185$, Fig. 1a).

Of the 28 females yielding data on incubation rhythm, 18 females were successful in hatching. Recess duration and number of recesses were significantly different between the successful and unsuccessful females $(\mathrm{df}=1512, t=3.131, p=0.002$ and $\mathrm{df}=338.771, t=2.863$, $p=0.005$ respectively, $T_{\text {successful }}=20.7 \pm 8.2 \mathrm{~min}$,
$T_{\text {unsuccessful }} 19.5 \pm 6.7 \quad \min , \quad N_{\text {successful }}=5.1, \quad N_{\text {unsuccess }}$ ful $=4.8$ ). Successful females took more and longer recesses. Twenty of 28 females were followed with transmitters. There was no difference in number of recesses between those that were tracked and those that were not $\left(N_{\text {tracked }}=5.0, \quad N_{\text {untracked }}=5.1, \quad \mathrm{df}=188.791, \quad t=-1.024\right.$, $p=0.299)$, however, tracked individuals had longer recess durations $\left(T_{\text {tracked }}=20.8, T_{\text {untracked }}=19.0, \mathrm{df}=1063.200\right.$, $t=4.591, p<0.001)$.

\section{Discussion}

In Willow Ptarmigan (Lagopus lagopus), as in many other ground-nesting precocial birds, the greatest attrition in fecundity is the loss of eggs to predators (Martin et al. 1989). Shorter laying period would reduce the 

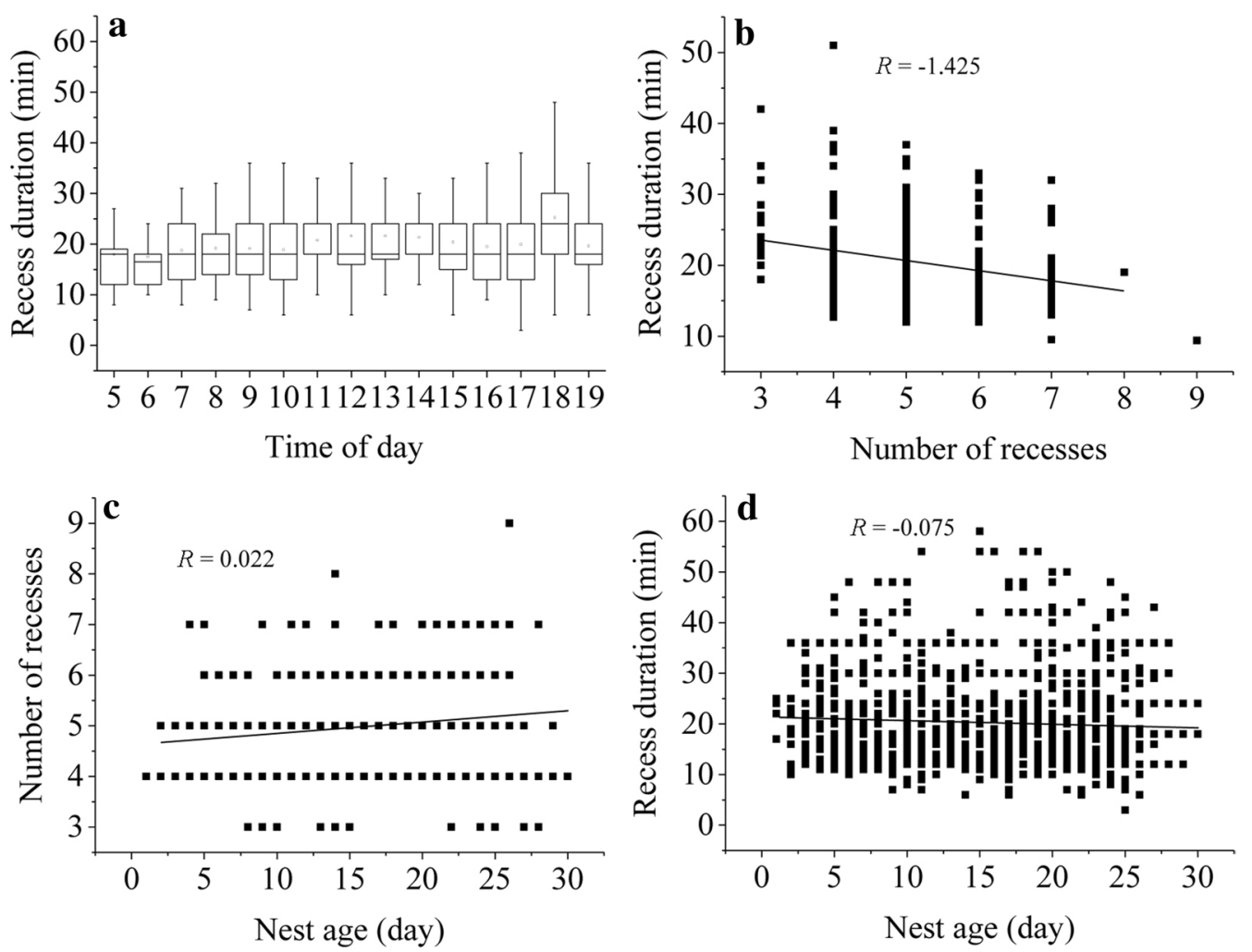

Fig. 1 Relationship between two measures of incubation behaviour (untransformed) and recess duration (a, $\mathbf{b})$, and between two measures of incubation behaviour and nest age $(\mathbf{c}, \mathbf{d})$

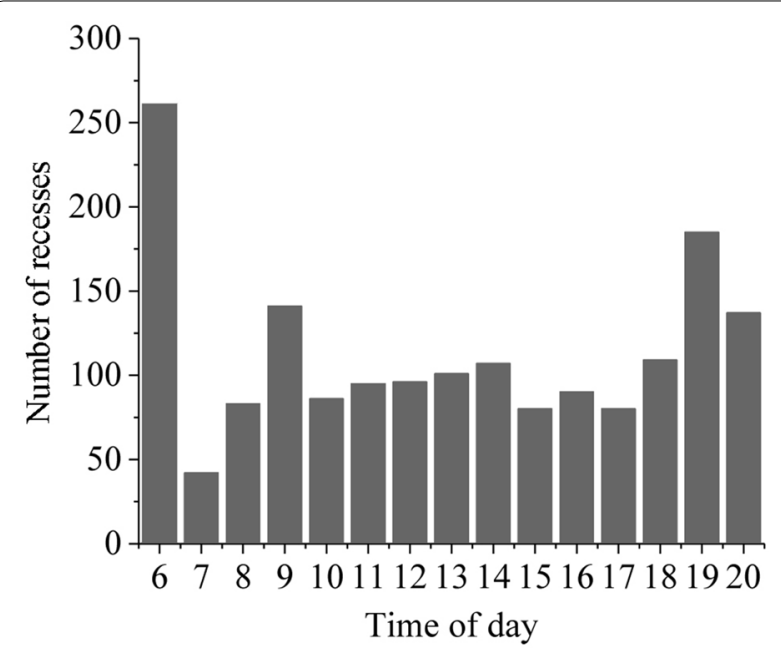

Fig. 2 Chinese Grouse nest recesses distribution in time of day at Lianhuashan Nature Reserve, Gansu, China. Data from data loggers and cameras show same trend

chances of egg predation (Clark and Wilson 1981); however, birds have limited energy reserve in their body and must gain additional energy by feeding, especially for precocial birds, because they produce eggs with more yolk (Carey et al. 1980) and might need more time for egg production. Egg-laying interval is thought to be a balance between egg size, clutch size, and time for laying the eggs (Schubert and Cooke 1993). The Chinese Grouse has the smallest body mass in the grouse sub-family (Tetraoninae). The average mass for the females is $327.4 \pm 26.3 \mathrm{~g}$ $(n=55$, Sun et al. 2005). The mass of Chinese Grouse eggs averages $20.5 \pm 1.6(n=165$, Sun et al. 2005), yielding egg/body mass ratio of 6.1-6.9\%, which is the highest among the grouse (Johnsgard 1983). Thus, Chinese Grouse should be physiologically stressed by egg production. The laying interval we documented was $49 \mathrm{~h}$ for the Chinese Grouse, longer than other grouse species, such as Willow Ptarmigan (24 h, Wiebe and Martin 1995), White-tailed Ptarmigan (Lagopus leucurus) (26 and 44 h, Wiebe and Martin 1995), Rock Ptarmigan (Lagopus mutus) (36 h, Watson 1972), Ruffed Grouse (Tetrastes umbellus) (36 h, Bump et al. 1947), and Hazel Grouse (T. bonasia) (31 h, Pynnönen 1954; Semenov-Tyan-Shanskii 1960) (Table 2). The average clutch size of the Chinese Grouse is 6.19 (Sun et al. 2003, first clutch), so the bird needs more than 12 days to lay a clutch. We suggest that 
Table 2 Reported reproductive parameters between grouse species

\begin{tabular}{|c|c|c|c|c|c|c|c|c|c|}
\hline Species & $\begin{array}{l}\text { Body weight } \\
\text { (g) }\end{array}$ & $\begin{array}{l}\text { Egg laying } \\
\text { interval } \\
\text { (h) }\end{array}$ & Clutch size & $\begin{array}{l}\text { Egg weight } \\
\text { (g) }\end{array}$ & $\begin{array}{l}\text { Incubation } \\
\text { (days) }\end{array}$ & $\begin{array}{l}\text { Incubation } \\
\text { constancy } \\
(\%)\end{array}$ & $\begin{array}{l}\text { Number } \\
\text { of daily } \\
\text { recesses }\end{array}$ & $\begin{array}{l}\text { Recess } \\
\text { duration } \\
\text { (min) }\end{array}$ & References $^{\mathrm{a}}$ \\
\hline $\begin{array}{l}\text { Chinese } \\
\text { Grouse } \\
\text { (Tetrastes } \\
\text { sewerzowi) }\end{array}$ & 327.4 & 49 & 6.19 & 20.5 & $28-31$ & 92.8 & 5.0 & 20.25 & 1 \\
\hline $\begin{array}{l}\text { Willow } \\
\text { Ptarmigan } \\
\text { (Lagopus } \\
\text { lagopus) }\end{array}$ & $525-652$ & 24 & $7.1,10.2$ & 23 & $21-22$ & & & & 2,3 \\
\hline $\begin{array}{l}\text { White-tailed } \\
\text { Ptarmigan } \\
\text { (Lagopus } \\
\text { leucurus) }\end{array}$ & 329 & $26-44$ & 5.9 & 21 & $22-23$ & $95.7,93.9$ & 3.07 & & $2,3,4$ \\
\hline $\begin{array}{l}\text { Rock Ptarmi- } \\
\text { gan (Lago- } \\
\text { pus mutus) }\end{array}$ & $427-701$ & 36 & 6.6 & 21 & 21 & & & & 2,5 \\
\hline $\begin{array}{l}\text { Ruffed Grouse } \\
\text { (Bonasa } \\
\text { umbellus) }\end{array}$ & $500-586$ & 36 & 11.5 & 19 & 24 & 96 & 2.0 & $20-40$ & $2,6,7$ \\
\hline $\begin{array}{l}\text { Hazel Grouse } \\
\text { (Tetrastes } \\
\text { bonasia) }\end{array}$ & $370-422$ & 31 & 8.3 & 19 & $23-27$ & 95 & 2.0 & 33 & $2,8,9$ \\
\hline $\begin{array}{l}\text { Blue Grouse } \\
\text { (Dendra- } \\
\text { gapus } \\
\text { obscurus) }\end{array}$ & $813-867$ & & 6.37 & 33 & 26 & & & & 2 \\
\hline $\begin{array}{l}\text { Greater } \\
\text { Sage-grouse } \\
\text { (Centrocer- } \\
\text { cus uropha- } \\
\text { sianus) }\end{array}$ & 770 & & 12 & 24 & 26.5 & 96.1 & 2.2 & 26.5 & 2,10 \\
\hline $\begin{array}{l}\text { Spruce Grouse } \\
\text { (Dendra- } \\
\text { gapus } \\
\text { canadensis) }\end{array}$ & $456-620$ & & $5.8,7.54$ & 23 & $21-25$ & & & 26.4 & 2,11 \\
\hline $\begin{array}{l}\text { Capercail- } \\
\text { lie (Tetrao } \\
\text { urogallus) }\end{array}$ & $1755-2004$ & & 7.07 & 48 & $24-28$ & & & 35 & 2 \\
\hline
\end{tabular}

a The references refer to as follows: 1. Sun (2000), 2. Johnsgard (1983), 3. Wiebe and Martin (1995), 4. Wiebe and Martin (1997), 5. Watson (1972), 6. Bump et al. (1947), 7. Maxson (1977), 8. Semenov-Tyan-Shanskii (1960), 9. Müller (1992), 10. Coates and Delehanty (2008), 11. Naylor et al. (1988)

the relatively long egg interval in Chinese Grouse is due to relatively high physiological costs of egg production.

The laying time of Chinese Grouse was concentrated around noon. It is different from Hazel Grouse, which lays their eggs during 04:00-20:00 (Semenov-TyanShanskii 1960) and the ptarmigans, which lay eggs during 07:00-19:00 (Wiebe and Martin 1995). In 11\% failed nests, we identified three nest predator species using infrared video cameras: Asian Badger (Meles leucurus) accounting for three nest failures, Hog Badger (Arctonyx collaris) for one nest failure, and Blue-eared Pheasant (Crossoptillon auritum) for one nest failure. Badgers, the main nest predators in our study area were active in the evening-night period, so around noon might be the safest time for the Chinese Grouse to visit their nests. The length of the egg-laying interval (around $48 \mathrm{~h}$ ) also permitted all eggs to be laid around noon. Partial incubation existed especially in the late period of egg laying. White-tailed Ptarmigan and Spruce Grouse (Dendragapus canadensis) also showed this pattern (McCourt et al. 1973; Giesen and Braun 1979). In anseriforms and galliforms species, incubation starts during the laying period without causing hatching asynchrony (Wang and Beissinger 2011). Partial incubation thus shortens the incubation period and benefits incubating females (Wang and Beissinger 2011).

The incubation period of Chinese Grouse (around 28-31 days) was relatively long compared to Blue Grouse 
(Dendragapus obscurus, 26 days) Greater Sage-grouse (Centrocercus urophasianus, 26.5 days) Hazel Grouse (23-27 days) and Spruce Grouse (21-25 days) (Johnsgard 1983) (Table 2). During incubation period, female Chinese Grouse spent on average $92.8 \%$ of their time per day on nest, which was lowest in grouse species: Ruffed Grouse (96\%, Maxson 1977), White-tailed Ptarmigan (95.7\% and 93.9\%, Wiebe and Martin 1997), Greater SageGrouse (96.1\%, Coates and Delehanty 2008) and Hazel Grouse (95\%, Semenov-Tyan-Shanskii 1960) (Table 2). The number of daily recesses taken by Chinese Grouse females averaged 5.0, much higher than that of the Hazel Grouse (2.0, Müller 1992), and White-tailed Ptarmigan (3.07, Wiebe and Martin 1997). The average recess duration of Chinese Grouse was 20.25 min, shorter than that of Spruce Grouse (26.4 min, Naylor et al. 1988), Hazel Grouse (33 min, Müller 1992), Capercaillie (Tetrao urogallus) (35 min), and Ruffed Grouse (20-40 min, Johnsgard 1983) (Table 2). And our result showed the number of recesses was negatively related to recess duration. The incubating females might adjust recess duration to guarantee incubation attendance. Chinese Grouse therefore showed a pattern of a long incubation period with low incubation constancy, and more and shorter recesses.

Theory predicts shorter embryonic periods in species with smaller body size (Martin et al. 2007). However, Martin (2002) found no relationship between body mass and incubation period, and proposed that longer incubation periods were associated with lower attentiveness. Deeming et al. (2006) also believed that nest attentiveness affected egg temperature maintenance, and resulted in incubation period variation. Cartar and Montgomerie (1985) suggested that small-bodied incubators have a low fasting endurance and modified nest attentiveness by adjusting the frequency of recesses. Our results support their proposals. With small body mass, females have less endogenous reserves and more nutritional requirements (Demment and Vansoest 1985; Swenson et al. 1994). Limited by energy reserve, they have to leave their nests more often for foraging. Studies have documented that parents compensate for energy demands by reducing nest attentiveness (MacDonald et al. 2014). These might be the reasons why breeding success was related to more and longer recesses in Chinese Grouse females.

Females who were tracked by transmitters (weighing about $12 \mathrm{~g}$, or $3-4 \%$ of their body weights, Sun et al. 2003) required longer recesses, presumably for more foraging. However, low attentiveness can decrease reproductive success (Mallory 2009; Shoji et al. 2011). Although we found no significant difference on reproductive success between tracked and untracked females, we believe that the additional burden of the transmitters might have adverse effects on the tracked females during incubation.

Our results showed differences in recess duration between years, which might be affected by environment temperatures and different monitoring methods. Method does affect recess duration (one-way ANOVA, $F=16.37$, $p<0.001, \quad T_{\text {datalog6 }}=21.32, \quad T_{\text {datalog } 1}=19.34, \quad T_{\text {cam }}$. era $=18.21)$. Data logger could overestimate the recess duration because of delayed temperature recording. But recess duration still has significant difference among years, when we excluded the effect of method. Many studies have shown that females take more and shorter recesses in cold environments (Conway and Martin 2000b; Londono et al. 2008; Reneerkens et al. 2011; MacDonald et al. 2014). The recess length of Chinese Grouse in $2001(17.37 \pm 6.23 \mathrm{~min})$ was shorter than that in 2000 $(21.06 \pm 7.06 \mathrm{~min})(t$ test, both $p<0.001)$. We recorded the air temperature in 2000 and 2001 . The daily average air temperature during incubation was significantly lower in $2001\left(5.4 \pm 1.6{ }^{\circ} \mathrm{C}\right)$ than in $2000\left(8.5 \pm 2.1{ }^{\circ} \mathrm{C}\right)(t$ test, $p<0.001)$. As the daily number of recesses was higher in $2001(5.37 \pm 0.96, n=249)$ than in $2000(5.09 \pm 0.95$, $n=540)$ ( $t$ test, $p=0.093$ ), we suggest that the Chinese grouse females adjust incubation rhythm to adapt environment constraints. This correlation has also been found in other grouse species, such as the Spruce Grouse (Naylor et al. 1988). However, studies on the Capercaillie showed that cold weather did not affect the number and length of recesses for this largest grouse (Semenov-TyanShanskii 1960).

Fluctuations in temperature are more detrimental to eggs as incubation progresses (Webb 1987). Meanwhile, the rate of heat loss from eggs increases with embryo age (Cooper and Voss 2013). Female Black-capped Chickadee (Poecile atricapillus) responds to increased egg cooling rates by altering incubation rhythms (with more frequent and shorter on- and off-bouts) (Cooper and Voss 2013). The Chinese Grouse females also reduced the recess length as the incubation progressed. However, the daily inattentive period did not differ. For incubating females, body mass has been associated with food abundance (Quillfeldt et al. 2006), and positively related to reproductive success (Gloutney and Clark 1991). In the latter period of incubation, their foraging requirement might be more urgent, as adequate feeding is essential for reproductive success. So, female Chinese Grouse might increase the frequency of recesses and shorten recess duration. Similar results were also found in the Wood Duck (Aix spons) (Hepp et al. 1990).

A bimodal pattern of recess timing may not be driven primarily by predation pressure, but by physiological needs of the incubating female (Winder et al. 2016). Female grouse may have a greater energy demand at 
dawn after fasting overnight, and take recesses at dusk to obtain energy reserves for overnight hours (Wiebe and Martin 1997). Successful females took more and longer recesses, which is at odds with the view that fewer trips to and from the nest may attract fewer predators to the eggs (Ghalambor and Martin 2002). In addition, radio-tracked females increased food intake to cover the additional burden of carrying the transmitter. We suggest that the energy needs of the incubating female are more important than egg chilling and predation risk. We conclude that the egg laying and incubation rhythm of the Chinese Grouse is an adaption mainly to deal with energy stress, with predation risk being of less importance.

\section{Conclusion}

We conclude that the egg laying and incubation rhythms of Chinese Grouse are driven by energy constraints. Compared with other grouse, female Chinese Grouse take longer egg laying intervals, leave nests more times per day with lower incubation attentiveness and longer incubation period to balance the thermal needs of the developing embryos and their self-maintenance needs.

\section{Acknowledgements}

We thank people in the Lianhuashan Natural Reserve for their great helps. Prof. Kathy Martin gave us great comments on our manuscript. We appreciate all these help for the improvement of this paper.

\section{Authors' contributions}

MS and YHS conceived and designed the idea. YF, JMZ, YXJ and MS performed the field work. MS, JS and SK analyzed the data. MS and YHS wrote the paper. All authors contributed critically to the manuscript and gave final approval for publication. All authors read and approved the final manuscript.

\section{Funding}

This study was supported by grants of the National Natural Science Foundation of China (31520103903, 31172099), CAS Innovation Program and Deutsche Forschungs-emeinschaft and World Pheasant Association.

\section{Availability of data and materials}

The datasets generated and/or analyzed during the current study are available from the corresponding author on reasonable request.

\section{Ethics approval and consent to participate}

All capture, radio-tag and tracking procedures on Chinese Grouse used in the present study had been given prior approval and were supervised by the Animal Care and Use Committee of the Institute of Zoology, the Chinese Academy of Sciences (Project No. 2008/73).

\section{Consent for publication}

Not applicable.

\section{Competing interests}

The authors declare that they have no competing interests.

\section{Author details}

${ }^{1}$ Key Laboratory of Animal Ecology and Conservation Biology, Institute of Zoology, Chinese Academy of Sciences, Beijing 100101, China. ${ }^{2}$ University of Chinese Academy of Sciences, Beijing 100049, China. ${ }^{3}$ School of Life
Science, Huaibei Normal University, Huaibei 235000, China. ${ }^{4}$ Jena, Germany.

${ }^{5}$ Faculty of Environmental Sciences and Natural Resource Management, Norwegian University of Life Sciences, Box 5003, 1432 Ås, Norway.

Received: 15 May 2019 Accepted: 30 May 2019

Published online: 14 June 2019

\section{References}

Afton AD. Factors affecting incubation rhythms of Northern Shovelers. Condor. 1980;82:132-7.

Bump GR, Darrow W, Edminster FC, Crissey WF. The Ruffed Grouse. Buffalo: Holling Press; 1947.

Camfield AF, Pearson SF, Martin K. Life history variation between high and low elevation subspecies of horned larks Eremophila spp. J Avian Biol. 2010;41:273-81.

Carey C, Rahn H, Parisi P. Calories, water, lipid and yolk in avian eggs. Condor. 1980;82:335-43.

Cartar RV, Montgomerie RD. The influence of weather on incubation scheduling of the white-rumped sandpiper (Calidris fuscicollis): a uniparental incubator in a cold environment. Behaviour. 1985;95:261-89.

Chalfoun AD, Martin TE. Latitudinal variation in avian incubation attentiveness and $a$ test of the food limitation hypothesis. Anim Behav. 2007:73:579-85.

Clark AB, Wilson DS. Avian breeding adaptations: hatching asynchrony, brooding reduction, and nest failure. Q Rev Biol. 1981;56:253-77.

Coates PS, Delehanty DJ. Effects of environmental factors on incubation patterns of Greater Sage-Grouse. Condor. 2008;110:627-38.

Conway CJ, Martin TE. Effects of ambient temperature on avian incubation behavior. Behav Ecol. 2000a;11:178-88.

Conway CJ, Martin TE. Evolution of passerine incubation behavior: Influence of food, temperature, and nest predation. Evolution. 2000b;54:670-85.

Cooper CB, Voss MA. Avian incubation patterns reflect temporal changes in developing clutches. PLoS ONE. 2013;8(6):1-6.

Cucco M, Malacarne $\mathrm{G}$. The effect of supplemental food on time budget and body condition in the Black Redstart Phoenicurus ochruros. Ardea. 1997;85(2):211-21.

Deeming DC, Birchard GF, Crafer R, Eady PE. Egg mass and incubation period allometry in birds and reptiles: effects of phylogeny. J Zool. 2006;270(2):209-18.

Demment MW, Vansoest PJ. A nutritional explanation for body-size patterns of ruminant and nonruminant herbivores. Am Nat. 1985:125(5):641-72.

Ghalambor CK, Martin TE. Comparative manipulation of predation risk in incubating birds reveals variability in the plasticity of responses. Behav Ecol. 2002;13(1):101-8.

Giesen KM, Braun CE. Nesting behaviour of the female white-tailed ptarmigan in Colorado. Condor. 1979;81:215-7.

Gloutney ML, Clark RG. The significance of body-mass to female Dabbling Ducks during late incubation. Condor. 1991;93:811-6.

Hepp GR, Kennamer RA, Harvey WF. Incubation as a reproductive cost in female wood ducks. Auk. 1990;107:756-64.

Johnsgard PA. The grouse of the world. Lincoln: University of Nebraska Press; 1983. p. 13-9.

Londono GA, Levey DJ, Robinson SK. Effects of temperature and food on incubation behaviour of the northern mockingbird, Mimus polyglottos. Anim Behav. 2008;76:669-77.

Lou YQ, Shi M, Fang Y, Swenson JE, Lyu N, Sun YH. Male vigilance and presence are important for foraging by female Chinese grouse in the pre-incubation period. Wildl Biol. 2017;1(Suppl):1-6.

MacDonald EC, Camfield AF, Jankowski JE, Martin K. An alpine-breeding songbird can adjust dawn incubation rhythms to annual thermal regimes. Auk. 2014;131:495-506.

Mallory ML. Incubation scheduling by Northern Fulmars (Fulmarus glacialis) in the Canadian High Arctic. J Ornithol. 2009;150:175-81.

Manlove CA, Hepp GR. Patterns of nest attendance in female wood ducks. Condor. 2000;102:286-91.

Martin K, Hannon SJ, Rockwell RF. Clutch size variation and patterns of attrition in fecundity of Willow Ptarmigan. Ecology. 1989;70:1788-99.

Martin TE, Auer SK, Bassar RD, Niklison AM, Lloyd P. Geographic variation in avian incubation periods and parental influences on embryonic temperature. Evolution. 2007;61:2558-69. 
Martin TE. A new view of avian life-history evolution tested on an incubation paradox. Proc R Soc B Biol Sci. 2002;269:309-16.

Maxson SJ. Activity patterns of female ruffed grouse during the breeding season. Wilson Bull. 1977;89:439-55.

McCourt KH, Boag DA, Keppie DM. Female spruce grouse activities during laying and incubation. Auk. 1973;90:619-23.

Müller U. Aktivitätsuntersuchungen an freilebenden Haselhühnern (Bonasa bonasia L. 1758). Diplomarbeit. Freiburg, Germany: University of Freiburg. 1992.

Naylor BJ, Szuba KJ, Bendell JF. Nest cooling and recess length of incubating spruce grouse. Condor. 1988;90:489-92.

Persson I, Göransson G. Nest attendance during egg laying in pheasants. Anim Behav. 1999:58:159-64.

Piersma T, Lindstrom A, Drent RH, Tulp I, Jukema J, Morrison RIG, Reneerkens J, Schekkerman $H$, Visser GH. High daily energy expenditure of incubating shorebirds on High Arctic tundra: a circumpolar study. Funct Ecol. 2003;17:356-62.

Pynnönen A. Beiträge zur Kenntnis der Lebensweise des Haselhuhns, Tetrastes bonasia (L.). Pap Game Res. 1954;12:1-90.

Quillfeldt P, Masello JF, Lubjuhn T. Variation in the adult body mass of Wilson's storm petrels Oceanites oceanicus during breeding. Polar Biol. 2006;29:372-8.

Reneerkens J, Grond K, Schekkerman H, Tulp I, Piersma T. Do Uniparental Sanderlings Calidris alba increase egg heat input to compensate for low nest attentiveness? PLOS ONE. 2011;6:1-9.

Schubert CA, Cooke F. Egg-laying intervals in the Lesser Snow Goose. Wilson Bull. 1993;105:414-26.

Semenov-Tyan-Shanskii O. Ekologiya teterevinykh ptits. Trudy Laplandskogo Gosudarstvennogo Zapovednika. 1960:5:1-318 (in Russian)

Shoji A, Elliott KH, Aris-Brosou S, Crump D, Gaston AJ. Incubation patterns in a central-place forager affect lifetime reproductive success: Scaling of patterns from a foraging bout to a lifetime. PLoS ONE. 2011;6:1-10.

Sun YH. Distribution and status of the Chinese grouse Bonasa sewerzowi. Wildl Biol. 2000;6:271-5.

Sun YH, Swenson JE, Fang Y, Klaus S, Scherzinger W. Population ecology of the Chinese grouse, Bonasa sewerzowi, in a fragmented landscape. Biol Conserv. 2003;110:177-84.
Sun YH, Fang Y, Swenson JE, Klaus S, Zheng GM. Morphometrics of the Chinese grouse Bonasa sewerzowi. J Ornithol. 2005;146:24-6.

Swenson JE, Saari L, Bonczar Z. Effects of weather on Hazel Grouse reproduction—an allometric perspective. J Avian Biol. 1994;25:8-14.

Vleck CM. Hummingbird incubation-female attentiveness and egg temperature. Oecologia. 1981;51:199-205.

Watson A. The behaviour of the ptarmigan. Brit Birds. 1972;65:6-26.

Wang J, Chen Y, Lu N, Fang Y, Sun YH. Diet of Chinese Grouse (Tetrastes sewerzowi) during preincubation. Wilson J Ornithol. 2010:122:177-80.

Wang JM, Beissinger SR. Partial incubation in birds: its occurrence, function, and quantification. Auk. 2011;128:454-66.

Webb DR. Thermal tolerance of avian embryos: a review. Condor. 1987:97:708-17.

Wiebe K, Martin K. Ecological and physiological effects on egg laying intervals in ptarmigan. Condor. 1995;97:708-17.

Wiebe K, Martin K. Effects of predation, body condition and temperature on incubation rhythms of white-tailed ptarmigan Lagopus leucurus. Wild Biol. 1997:3:219-27.

Wiebe K, Martin K. The use of incubation behaviour to adjust avian reproductive costs after egg laying. Behav Ecol Sociobiol. 2000:48:463-70.

Winder VL, Herse MR, Hunt LM, Gregory AJ, McNew LB, Sandercock BK. Patterns of nest attendance by female Greater Prairie-Chickens (Tympanuchus cupido) in northcentral Kansas. J Ornithol. 2016;157(3):733-45.

Zhao JM, Fang Y, Ma YH, Sun YH. The importance of willow to the Chinese Grouse: evidence from analysis on their breeding territories at Lianhuashan, China. Avian Res. 2017;8:32.

Zhao JM, Fang Y, Lou YQ, Swenson JE, Sun YH. Brood rearing has an immediate survival cost for female Chinese grouse tetrastes sewerzowi. J Ornithol. 2018;159:1019-29.

Zhao JM, Yang C, Lou YQ, Shi M, Fang Y, Sun YH. Nesting season, nest age and disturbance, but not habitat characteristics affect nest survival of Chinese grouse. Curr Zool. 2019. https://doi.org/10.1093/cz/zoz024.
Ready to submit your research? Choose BMC and benefit from:

- fast, convenient online submission

- thorough peer review by experienced researchers in your field

- rapid publication on acceptance

- support for research data, including large and complex data types

- gold Open Access which fosters wider collaboration and increased citations

- maximum visibility for your research: over $100 \mathrm{M}$ website views per year

At $\mathrm{BMC}$, research is always in progress.

Learn more biomedcentral.com/submissions 